\title{
RANCANG BANGUN WEBSITE SEKOLAH TINGGI EKONOMI ISLAM (STEI) IQRA ANNISA SEBAGAI WADAH PENYEBARAN INFORMASI
}

\author{
Salamun \\ Teknik Informatika, Fakultas Teknik, Universitas Abdurrab Pekanbaru \\ Jl. Riau Ujung, Pekanbaru, 28282 \\ E-Mail:salamun@univrab.ac.id
}

\begin{abstract}
ABSTRAK
informasi seputar institusi sangat dibutuhkan oleh kalangan mahasiswa ataupun masyarakat, baik itu informasi tentang perkuliahan maupun informasi yang bersifat umum yang mana bertujuan untuk memberikanberita seputar kampus STEI Iqra Annisa Pekanbaru. Dalam penelitian ini membahas tentang bagaimana membuat sebuah wadah untuk mendapatkan informasi yang berguna bagi mahasiswa pada khususnya dan masyarakat pada umumnya. Dalam pembuatan website ini dilakukan beberapa observasi lapangan untuk mendapatkan informasi apa saja yang sedang dibutuhkan oleh masyarakat dan mahasiswa dari kampus STEI Iqra Annisa Pekanbaru. Dari hasil survey lapangan yang telah dilakukan, maka didapatlah sebuah kesimpuan bahwa pada saat ini informasi yang sangat dibutuhkan oleh mahasiswa adalah tentang jadwal perkuliahan, data dosen, informasi kegiatan terbaru dan informasi tentang kurikulum. Sedangkan bagi masyarakat umum, website dapat menyajikan informasi berupa seputar kegiatan kampus yang akan di adakan, maupun yang telah diadakan.
\end{abstract}

Kata Kunci : STEI Iqra Annisa, Informasi, website

\begin{abstract}
ABSTRAC
information about the institution is needed by the students or the public, whether it is information about lectures or general information which aims to provide news about the campus STEI Iqra Annisa Pekanbaru. In this study discuss about how to make a container to get useful information for students in particular and society in general. In making this website do some field observation to get information what is being needed by the community and students from the campus STEI Iqra Annisa Pekanbaru. From the results of field surveys that have been done, then got a conclusion that at this time the information that is needed by students is about lecture schedule, lecturer data, latest activity information and information about the curriculum. As for the general public, the website can provide information about the campus activities that will be held, or that have been held.
\end{abstract}

Keywords: STEI Iqra Annisa, Information, website

\section{PENDAHULUAN}

Pada saat sekarang ini harga sebuah informasi sangat ditentukan oleh kualitas dan sumber dari informasi tersebut. Dengan banyaknya penyedia laman web pada saat ini maka dapat memudahkan kita dalam mencari informasi yang diinginkan. Dalam malakukan penyebaran informasi pada media online memerlukan beberapa metode yang tepat dan menarik agar para pencari informasi tertarik dengan informasi yang disebarkan. Dengan perkembangannya zaman saat ini, maka semakin banyak pula tenaga ahli di bidang website menawarkan jasa untuk menyediakan web pada instansi, perusahaan maupun sekolah. Dalam meyebarkan sebuag informasi pada laman sebuah web sangat diperlukan sebuah informasi yang menarik, singkat padat dan tepat, karena pada saat sekarang ini banyak mahasiswa dan masyarakat sudah memahami tentang pentingnya sebuah informasi. Maka dari itu menyajikan informasi harus semenarik dan berita terbaru yang belum diketahui oleh para pembaca. Maka dari itu, Penulis memilih objek penelitian di STEI Iqra Annisa Pekanbaru. Berdasarkan penelusuran yang dilakukan penulis, informasi seputar kampus belum dapat 
diaksese dengan maksimal oleh mahasiswa dan masyarakat.

\section{Website}

website dapat diartikan sebagai situs web yang berisi mengenai berbagai jenis berita atau informasi, mulai dari berita seputar politik, dalam negeri, luar negeri, olahraga hingga berita ringan. Portal berita terdiri dari dua kata, yaitu portal dan berita. Portal memiliki pengertian sebagai situs web, sedangkan berita dapat didefinisikan sebagai informasi terbaru mengenai sesuatu yang sedang terjadi yang disajikan melalui bentuk cetak, siaran, internet, atau dari mulut ke mulut kepada orang banyak. Jadi dapat disimpulkan bahwa portal berita adalah situs yang menampilkan informasi mengenai informasi yang terjadi ke masyarakat.[1]

\section{Informasi}

Informasi merupakan data atau fakta yang telah diproses sedemikian rupa, sehingga berubah bentuknya menjadi informasi. Di samping itu informasi dapat mengurangi ketidakpastian serta mempunyai nilai dalam keputusan karena dengan adanya informasi kita dapat memilih tindakan-tindakan dengan resiko yang paling kecil. [2]

\section{Context Diagram}

Menurut Kendall dan Kendall (2003:263), diagram aliran data menggambarkan padangan sejauh mungkin mengenai masukan, proses, dan keluaran sistem, yang berhubungan dengan masukan, proses, dan keluaran dari model sistem umum.[3]

\section{STEI Iqra Annisa Pekanbaru}

STEI Iqra Annisa Pekanbaru merupakan salah satu sekolah tinggi di bidang ekonomi islam yang ada di Pekanbaru-Riau, tepatnya di Jl. Riau Ujung No 73 Pekanbaru. Yayasan
Iqra Annisa ini di ketuai oleh Dr.dr. Hj. Susiana, M.PdI yang sudah mendapatkan izin operasional pada tahun 2005 dari koordinator perguruan tinggi agama islam wilayah riau (KOPERTAIS). STEI Iqra Annisa sudah memiliki areditasi dengan predikat Baik (B) dari BAN-PT.

\section{METODE}

Pada metode pengembangan sistem pada penelitian menerapkan metode Waterfall Model (model air terjun) sebagai metode pengembang. "Sistem Waterfall Model adalah suatu pendekatan pengembangan sistem yang sederhana.[4]

Model air terjun ini mempunyai kegiatan proses dasar spesifikasi, pengembangan, validasi, dan evolusi dan mewakili mereka sebagai fase proses terpisah seperti spesifikasi persyaratan, desain perangkat lunak, implementasi, pengujian, dan sebagainya.

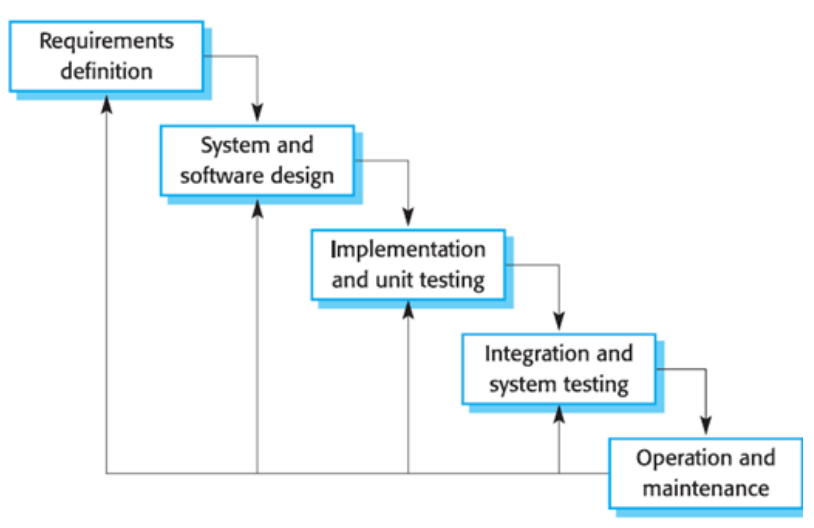

Gambar 1. Waterfall Method

Tahapan utama dari model air terjun langsung mencerminkan kegiatan pembangunan sistem perangkat lunak yang mendasar :

1. Persyaratan analisis dan definisi, Layanan sistem, kendala, dan tujuan yang ditetapkan oleh konsultasi dengan 
pengguna sistem. Mereka kemudian didefinisikan secara rinci dan fungsi sebagai spesifikasi sistem.

2. Sistem dan desain perangkat lunak, Proses desain sistem mengalokasikan persyaratan baik untuk perangkat keras atau perangkat lunak sistem dengan membentuk arsitektur sistem secara keseluruhan. Desain perangkat lunak melibatkan identifikasi dan menggambarkan abstraksi sistem perangkat lunak yang mendasar dan hubungan mereka.

3. Implementasi dan pengujian unit, Selama tahap ini, desain perangkat lunak direalisasikan sebagai serangkaian program atau unit program. Unit pengujian melibatkan verifikasi bahwa setiap unit memenuhi spesifikasinya.

4. Integrasi dan pengujian sistem, Unit program individu atau program yang terintegrasi dan diuji sebagai sistem yang lengkap untuk memastikan bahwa persyaratan perangkat lunak telah dipenuhi. Setelah pengujian, sistem perangkat lunak disampaikan kepada pelanggan.

5. Operasi dan pemeliharaan, Biasanya (meskipun tidak selalu), ini adalah fase siklus hidup terpanjang. Sistem terinstal dan dimasukkan ke dalam penggunaan praktis. Pemeliharaan melibatkan mengoreksi kesalahan yang tidak ditemukan pada tahaptahap awal dari siklus hidup, meningkatkan pelaksanaan unit sistem dan meningkatkan layanan sistem sebagai persyaratan baru ditemukan.

Tahap berikut tidak bisa dimulai sampai tahap sebelumnya selesai. Dalam prakteknya, tahap ini tumpang tindih dan memberikan informasi satu sama lain. Selama desain, masalah dengan persyaratan diidentifikasi. Selama coding, masalah desain yang ditemukan dan sebagainya. Proses perangkat lunak tidak model linear sederhana namun melibatkan umpan balik dari satu fase ke yang lain. Dokumen yang dihasilkan di setiap tahap maka mungkin harus diubah untuk mencerminkan perubahan yang dibuat.

\section{HASIL}

Analisa Kebutuhan sistem digunakan untuk menjelaskan apa saja yang dibutuhkan dalam merancang sebuah sistem yang baru dan menggambarkan agar sesuai dengan kebutuhan pengguna, adapun analisa kebutuhan untuk Rancang Bangun websiteSTEI Iqra Annisa Pekanbaru adalah sebagai berikut:

\section{Analisa Kebutuhan Fungsional}

Sistem dapat menampilkan dan mengakses informasi umum tentang home, profile, Akademik, pengumuman, kurikulum, alumni dan jadwal perkuliahan serta informasi kegiatan kampus.

\section{Analisa kebutuhan non fungsional Spesipfikasi perangkat Keras}

Sistem dibangun dengan perangkat keras sebagai berikut: Processor minimal Intel dula core T6600 (2.20 GHz), Memory, DRAM 4048 MB, Hard disk : 500 GB, Keyboard, Mouse, Printer

\section{Spesipfikasi perangkat lunak}

Sistem dibangun dengan perangkat lunak sebagai berikut: Sistem operasi Microsoft Windows 7, MySQL sebagai perangkat lunak basis datanya (database), XAMPP sebagai web server,. Notepad++ untuk software editornya dan bahasa pemrograman PHP dan codeigniter web framework sebagai script utamanya.

\section{Desain Sistem Yang Berjalan Saat ini}

Perkembangan ilmu pengetahuan semakin pesat, dan mendorong kita untuk selalu berusaha meningkatkan dari apa yang 
terwujud saat ini. Mengimbangi pesatnya perkembangan ilmu pengetahuan dan teknologi salah satu diantaranya adalah dengan meningkatkan kualitas dan mutu sumber daya manusia yang dapat menangani berbagai masalah yang timbul seiring berkembangnya ilmu pengetahuan dan teknologi. Sistem yang sedang berjalan pada saat ini pada STEI Iqra Annisa Pekanbaru masih menggunakan cara lama, yaitu dengan cara memasang iklan pada surat kabar maupun melalui brosur untuk memberikan informasi seputar kampus.

\section{Sistem Yang Dikembangkan}

Sistem yang dikembangkan adalah sebuah sistem yang terkomputerisasi dalam bentuk website. Sistem yang dekembangkan dapat di gambarkan pada flowchart sistem di bawah ini:

Folowchart sistem memberikan gambaran bahwa, bagaimana sebuah sstem berjalan, mulai dari awal, proses, hingga akhir dari penggunaan sistem tersebut.

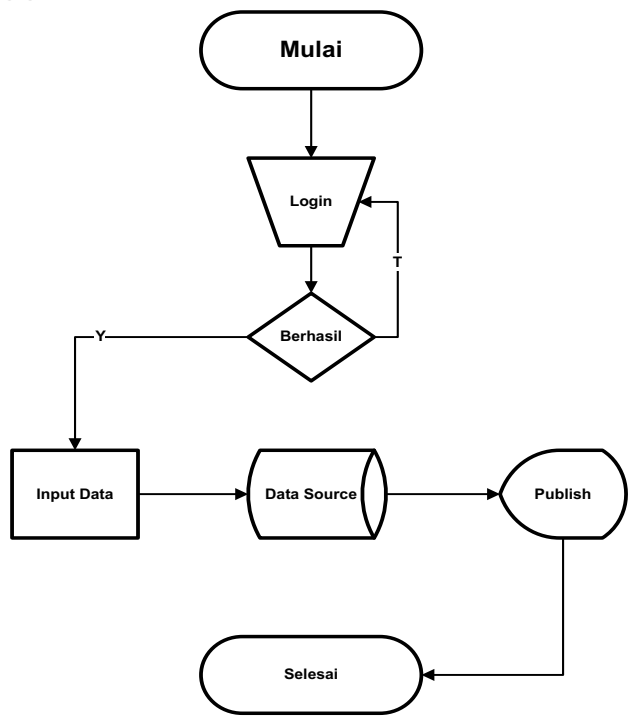

Gambar 2. Flowchart Sistem

\section{Diagram Konteks}

Pada perancangan sebuah sistem,maka perlu dibuat sebuah diagram konteks agar dapat melihat katifitas yang terlibat kedalam sistem

siapa saja dan apa saja yang dapat dilakukan oleh pengguna sistem tersebut, berikut ini merupakan gambaran konteks diagram dari website STEI Iqra Annisa yang sudah di rancang.

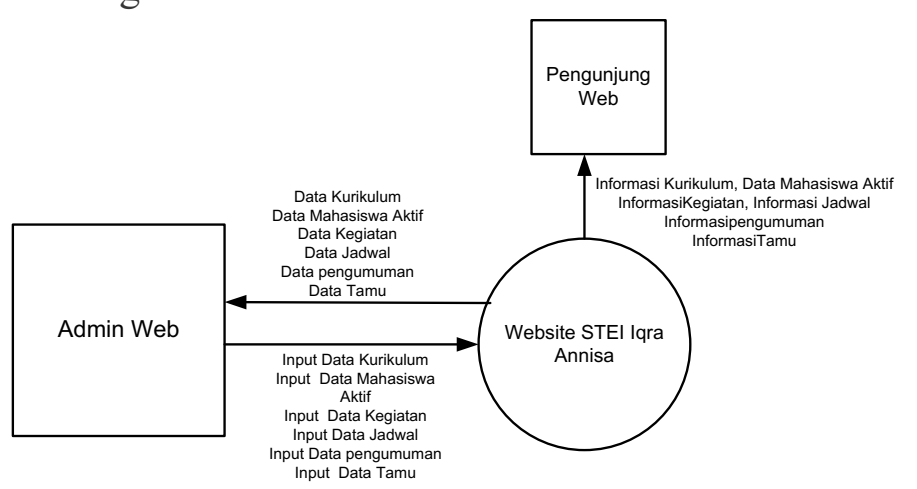

Gambar 3. Konteks Diagram Website STEI Iqra Annisa

\section{Implementasi Program}

Penerapan aplikasi website ini sudah langsung menggunakan hosting komersial yang mana alamat web sudah di daftarkan pada sebuah penyedia layanan hosting. Untuk alamat website dapat di akses melalui http://stei-iqra-annisa.ac.id/. Pada gambar 4. Merupakan tampilan awal untuk user atau pengunjung web.

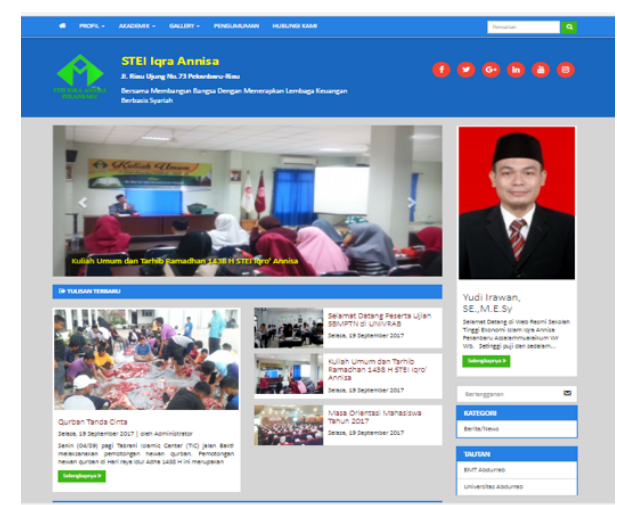

Gambar 4. Tampilan user

Pada gambar 5. Dibawah ini merupakan tamilan menu dropdown pada web, dimana terdapat beberapa menu yang bisa di aktifkan dan di non aktifkan oleh admin jika menu tersebut mau di tambah atau dikurangi. 


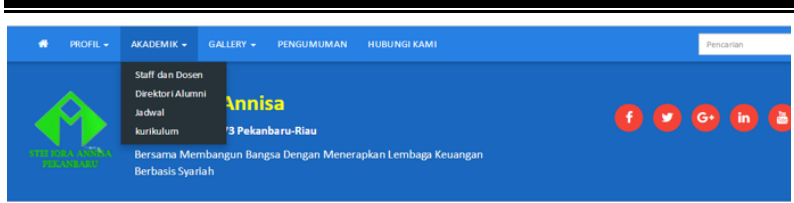

Gambar 5. Tampilan Menu Web

Pada gambar 6. Merupakan halaman administrator, dimana terdapat beberapa menu untuk mengelola website

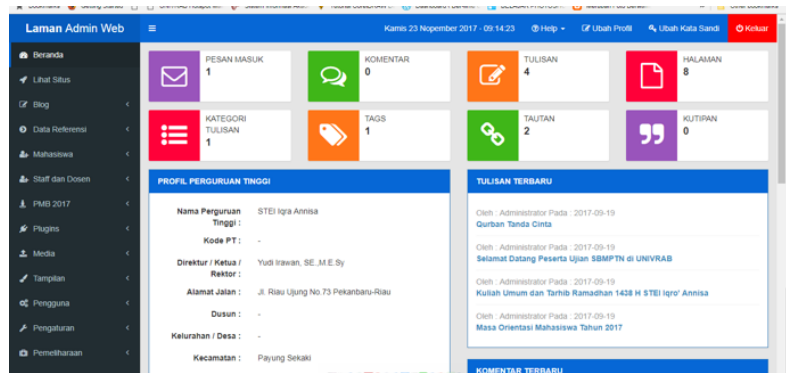

Gambar 6. Halaman administrator

Pada gambar 7. Merupakan fasilitas untuk menambah menu statis seperti, visi misi, profil, dan lain sebagainya, dimana nanti hasil dari pembuatan menu ini akan di tampilkan pada halaman user

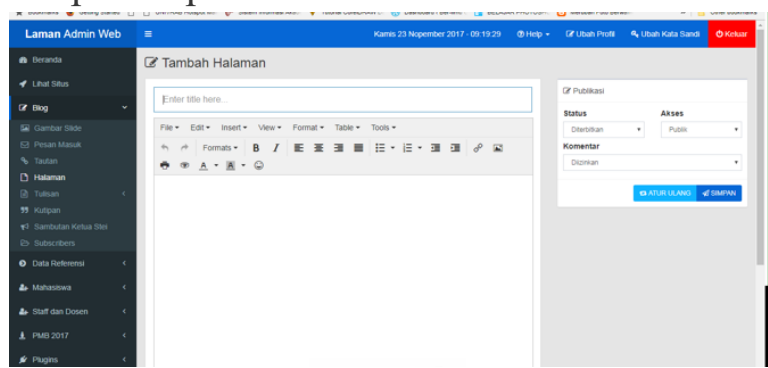

Gambar 7. Penambahan halaman/menu

Pada gambar 8. Merupakan fasilitas untuk menambah berita atau informasi yang terbaru, baik itu tentang seputar perkuliahan maupun tentang kegiatan-kegiatan yang akan atau yang telah dilakukan.

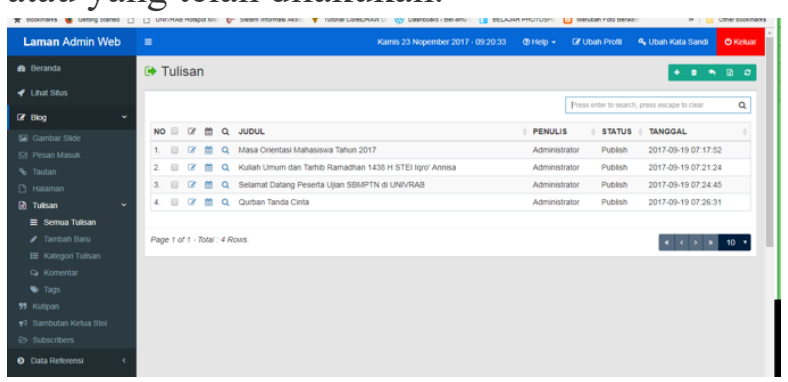

\section{Gambar 8. Laman tambah tulisan/berita}

Pada gambar 9. Merupakan form untuk menambah data dosen atau staff, data yang di inputkan disini nantinya akan di tampilkan pada laman utama website Stei Iqra Annisa Pekanbaru.

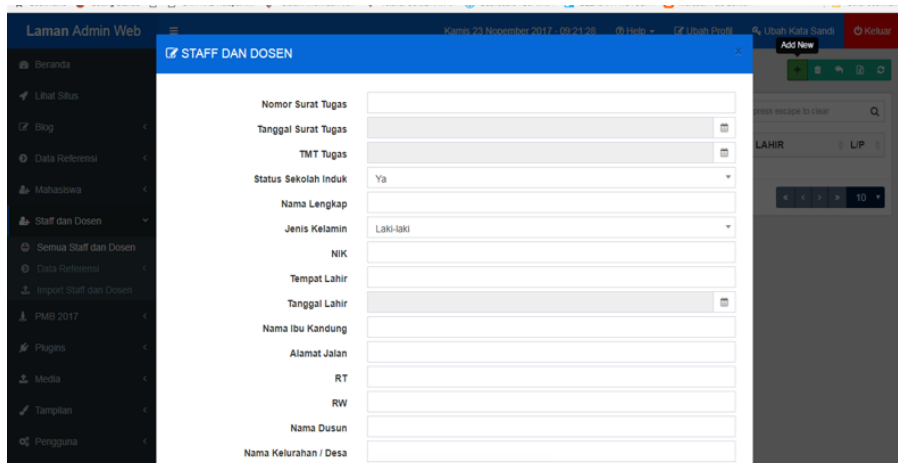

Gambar 9. Form input data dosen/staff

Pada gambar 10. Merupakan fasilitas form input data mahasiswa, pada form ini juga bisa merubah status mahasiswa yaitu, mahasiswa aktif, masa langkau, drop out dan sudah menjadi alumni

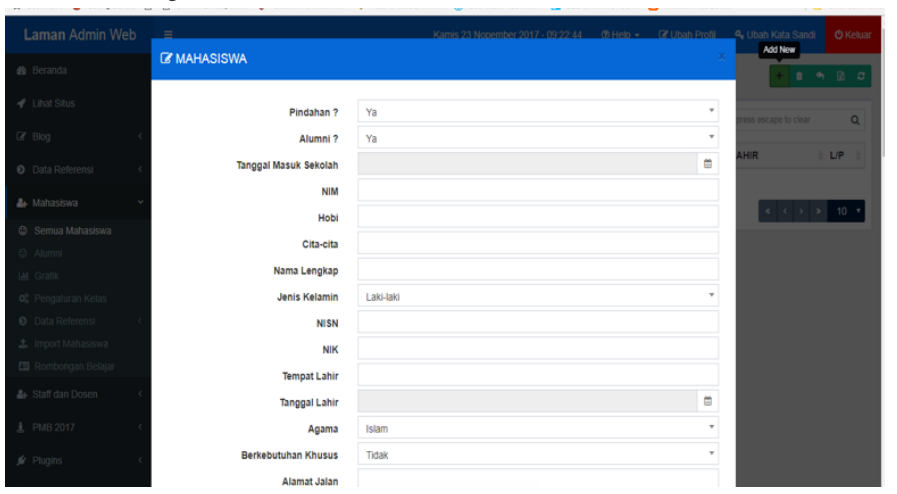

Gambar 10. Form input data mahasiswa

Pada gambar 11. Merupakan fasilitas untuk upload gambar yang mana akan di tampilkan ada menu galery di halaman user. 


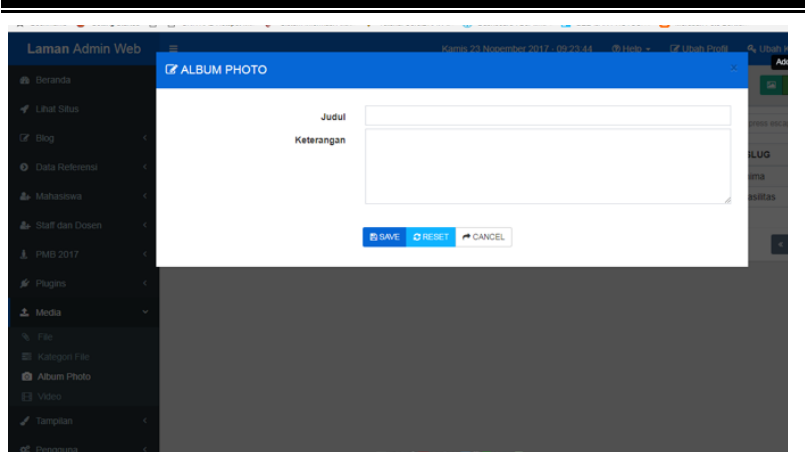

Gambar 11. Form tambah gambar

\section{KESIMPULAN}

Dengan adanya wadah berbagi informasi seperti website yang telah di buat maka di dapat beberapa kesimpulan yaitu sebagai berikut :

1. Mahasiswa akan lebih mudah mendapatkan informasi terbaru dari prodi baik itu tentang kurikulum, dosen maupun pengumuman terkait perkuliahan

2. Memudahkan masyarakat umum untuk mengakses informasi tentang kemajuan kampus Stei Iqra Annisa Pekanbaru.

3. Memberikan kemudahan kepada pihak akademik untuk menyebarkan berbagai informasi terkait dengan beberapa hal yaitu, kurikulum, kegiatan dan data mahasiswa.

4. Website yang dibangun meruakan website yang sudah responsive dimana memiliki tampian yang menarik dan juga mampu di akses di berbagai perangkat karena web bersifat responsive bagi pengguna.

5. Sudah tersedianya fasilitas informasi secara online di Stei Iqra Annisa Pekanbaru

\section{DAFTAR PUSTAKA}

[1] H. Triwardhono, D. O. Siahaan, T. Informatika, and F. T. Informasi, "Rancang Bangun Aplikasi Berita dan Informasi Pariwisata Indonesia Terkini dengan Menggunakan Kerangka Kerja PhoneGap," J. Tek. POMITS, vol. 2, no. 1, pp. 1-4, 2014.

[2] S. D. Anggadini, "Analisis Sistem Informasi Manajemen Berbasis Komputer dalam Proses Pengambilan Keputusan," Maj. Ilm. Unikom, vol. 11, no. 2, pp. 176-187, 2013.

[3] R. Universitas et al., "Jurnal Sistem Informasi Jurnal Sistem Informasi," Sist. Inf. UKM, vol. 6, no. 1, pp. 1206, 2013.

[4] M. Sudarmaji, "Rancang bangun majalah kampus online berbasis web," J. Inf. Politek. Indonusa Surakarta, vol. 1, pp. 53-59, 2015. 